\title{
Erratum to: Study of plasma off-gas treatment from spent ion exchange resin pyrolysis
}

\author{
Hernán Ariel Castro ${ }^{1,2} \cdot$ Vittorio Luca $^{1}$ Hugo Luis Bianchi ${ }^{2,3}$
}

Published online: 19 April 2017

(C) Springer-Verlag Berlin Heidelberg 2017

Erratum to: Environ Sci Pollut Res

DOI 10.1007/s11356-017-8766-2

The original publication of this paper contains an error.

The correct name of the 3rd Author is Hugo Luis Bianchi.

The online version of the original article can be found at http://dx.doi.org/ 10.1007/s11356-017-8766-2

$\triangle$ Hugo Luis Bianchi

bianchi@cnea.gov.ar

1 Programa Nacional de Gestión de Residuos Radiactivos, Comisión Nacional de Energía Atómica, Centro Atómico Constituyentes, Av. General Paz 1499, 1650 San Martín, Buenos Aires, Argentina

2 Escuela de Ciencia y Tecnología, Universidad Nacional de General San Martín, Campus Miguelete, Martín de Irigoyen 3100, 1650 San Martín, Argentina

3 Gerencia de Química, Comisión Nacional de Energía Atómica, Centro Atómico Constituyentes, Av. General Paz 1499, 1650 San Martín, Buenos Aires, Argentina 